\title{
Retraction Note: Marine climate characteristics and image pattern recognition based on global key node recognition
}

Lei Chen ${ }^{1}$

Published online: 24 November 2021

(c) Saudi Society for Geosciences 2021

Retraction Note: Arabian Journal of Geosciences (2021) 14: 1396

https://doi.org/10.1007/s12517-021-07704-0

The Editor-in-Chief and the Publisher have retracted this article because the content of this article is nonsensical. The peer review process was not carried out in accordance with the Publisher's peer review policy. The author has not responded to correspondence regarding this retraction.

The original article can be found online at https://doi.org/10.1007/ s12517-021-07704-0.

Lei Chen

C163L@163.COM

1 School of Computer Science and Communication

Engineering, Jiangsu University, Zhenjiang 212002, Jiangsu,

China 